\title{
The Role of Social Networks in Early Adoption of Mobile Devices
}

\author{
Heidi Tscherning ${ }^{1}$ and Lars Mathiassen ${ }^{2}$ \\ ${ }^{1}$ Center for Applied ICT, \\ Copenhagen Business School, \\ DK-2000 Frederiksberg, Denmark \\ ${ }^{2}$ Center for Process Innovation, \\ J. Mack Robinson College of Business, \\ Georgia State University, \\ Atlanta, Georgia, U.S.A.
}

\begin{abstract}
As mobile devices have become the personal information-processing interface of choice, many individuals seem to swiftly follow fashion. Yet, the literature is silent on how early adopters of mobile devices overcome uncertainties related to shifts in technology. Based on purposive sampling, this paper presents detailed insights into why and how five closely related individuals made the decision to adopt the iPhone before it was available through traditional supply chains. Focusing on the role played by social networks, we analyze how adoption threshold, opinion leaders, social contagion, and social learning shaped adoption behaviors and outcomes. The analyses confirm that network structures impact the early decision to accept the iPhone; they show that when facing uncertainty, adoption decisions emerged as a combined result of individual adoption reflections and major influences from the social network as well as behaviors observed within the network, and, they reveal interesting behaviors that differed from expectations. In conclusion, we discuss implications for both theory and practice.
\end{abstract}

Keywords: Adoption, social networks, adopter characteristics, qualitative research.

\section{Introduction}

Advanced mobile devices, such as smart phones and personal digital assistants, have become ubiquitously available and have changed the ways people organize relationships (Haddon 1997). Mobile users carry their device everywhere, they use it around the clock, and it has become their personal information-processing interface of choice. The symbolic value of these devices has increased, and many mobile users therefore swiftly follow fashion and change brand, as new devices and features become available. As a recent example, when Apple introduced the iPhone to the U.S. market in July 2007, 270,000 devices were sold in the first 30 hours of the launch 
weekend $^{1}$ and 8 million in total in the United States in the year 2007 (Brightman 2008). The original iPhone was subsequently made available in five other countries: the United Kingdom, Germany, and France in November 2007, and Ireland and Austria in March 2008. Early use of the iPhone was, however, not limited to these countries. Countless users around the world acquired an iPhone from the six official markets, and started to use it in their home countries. To do so, they needed to unlock the phone from the SIM-card and adapt it to network providers other than Apple's exclusive U.S. partner, AT\&T. During this period, one million iPhones, equivalent to 27 percent of the 2007 U.S. sales, were adapted to other networks. ${ }^{2}$

While shifts in technology occur regularly, change of technology brand bears several switching costs, including initial fixed costs, uncertainty about quality of device, as well as time spent on learning how to use the new technology (Hall and Kahn 2003). For early adopters, these costs are even higher as they have no references to imitate or expert users to consult. Nevertheless, the literature is silent on why and how individuals overcome these uncertainties as they decide to adopt a new voluntary technology such as a mobile device. Early adopters have imperfect information about the benefits of a new technology and their behavior, therefore, largely depends on acquired human capital, relevant information (Wozniak 1987), and in some cases also on access to unique technical skills (Hall and Kahn 2003).

Against this backdrop, this study investigates why and how five closely related individuals made the decision to adopt the iPhone before it was made available through traditional supply chains. Contextual factors, such as one's social environment, generally have significant impact on technology adoption and usage behaviors (Lewis et al. 2003; Magni et al. 2008). The role of social networks has also been used more broadly to understand social behavior (Van den Bulte and Lilien 2001; Vidgen et al. 2004) and information systems practices (Cambell and Russo 2003). Following these insights, our assumption is that a social network perspective will help us understand the context in which the five individuals managed to adopt the iPhone despite the many uncertainties they faced.

\section{Adoption of Mobile Devices}

Our research draws upon the specific literature on adoption of mobile devices as well as the general literature on individual adoption of communication technologies within information systems research. Adoption is the result of a decision-making process where an individual, group, or organization engages in activities that lead to a decision to use an innovation (Rogers 2003). Today's advanced devices combine communication and computing into a multipurpose gadget that provides users with various types of services (Bergman 2000). They furthermore have a one-to-one binding with the user, offer ubiquitous access, and provide a set of utilitarian and

1 Press Release, "iPhone Premieres This Friday Night at Apple Retail Stores," June 28, 2007, Apple, Inc. (http://www.apple.com/pr/library/2007/06/28iphone.html).

2 “Quarter of US iPhones 'Unlocked',” BBC News, January 29, 2008 (http://news.bbc.co.uk/1/hi/ business/7214873.stm). 
hedonic functions (Hong and Tam 2006). With this definition, we consider mobile services and applications as part of advanced mobile devices.

Since the early 1990s, research on mobile devices has gained increased attention as these devices were expected to "revolutionize many aspects of everyday life in the Western world" (Green et al. 2001, pp. 146). Adoption research has typically been centered on studies of either the artifact being adopted or the user setting. While adoption research in general has been criticized for a lack of attention to the attributes of the adopted devices and services (Orlikowski and Iacono 2001), few studies have considered the mobile artifact as an object of expression (Chuang et al. 2001) or as the related device design issues (Lee and Benbazat 2003; Tarasewitch 2003).

Historically, the majority of mobile users acquired their device through work, although this did not prevent private and leisure usage (Fisher 1994). Early studies have, therefore, in general studied mobile adoption in organizations, for example changes in organizational structure (Meehan 1998) and effects on the divide between work and leisure (Nippert-Eng 1996). Later work has also studied the blurring of work- and leisure-related functions of the mobile device (Palen et al. 2001) and the possibilities of business-to-business e-commerce (Wang and Cheung 2004). More recently, the focus has increasingly shifted toward individual adoption, as the mobile device has become the personal information-processing interface of choice. Studies are now concerned with the commercial possibilities: how mobile commerce exposure influences adoption (Khalifa and Cheng 2002); how users create value when adopting mobile banking services (Laukkanen and Lauronen 2005); which factors induce users to accept mobile devices to communicate promotional content (Bauer et al. 2005).

Pedersen and Ling (2002) suggest that adoption research in general "seeks explanations of why a particular adoption behavior may be observed at the individual level" (p. 9). They found rationalistic or utilitarian explanations, explanations based on social influence, and explanations focused on personal characteristics. Utilitarian studies use constructs such as usefulness and ease of use to measure individuals' willingness to adopt, exemplified by Carlsson et al.'s (2000) application of the UTAUT (unified theory of acceptance and use of technology) model to explain acceptance of mobile devices and services. Social influence explanations add elements of how social mechanisms influence individuals' adoption of a particular mobile device or service. One illustration is Lu et al.'s (2005) investigation of the relationships between personal innovativeness and social influences on one side and intention to adopt wireless Internet services via mobile technology on the other. Lu et al. also developed and validated measures for personal innovativeness, which is perceived as being a personal trait of adopters (Agarwal and Prasad 1999). There have also been efforts to describe different categories of adopters. Pedersen (2005) studied the adoption of mobile commerce of early adopters by extending the theory of planned behavior (TPB) with the technology acceptance model (TAM) constructs to explain early adoption of mobile commerce. Finally, Constantiou et al. (2007) developed a grouping that divides mobile users into distinct consecutive categories: talkers, writers, photographers, and surfers.

However, recent studies (Lyytinen and Yoo 2002; Sarker and Wells 2003) have called for research to further examine factors that explain the adoption of mobile devices. Against this backdrop, we are not aware of research that focuses on how 
early adopters of mobile devices leverage their social networks to overcome uncertainties related to shifts in technology. This gap in the literature limits our understanding of how early adoption decisions are shaped by an individual's peers and network.

\section{Social Network Influence}

A social network is a structure of individuals or organizations that are connected by some type of interdependency (Wasserman and Faust 1994). The relationship between the actors in the network depends on the context, as well as the research question being studied. Social influence is more meticulously defined as the "change in an individual's thoughts, feelings, attitudes, or behaviors that results from interaction with another individual or a group" (Rashotte 2007, p. 562). Earlier definitions included norms and roles (French and Raven 1959); however, the current notion is that individuals make genuine changes to their feelings and behaviors as a result of interaction with others, who are perceived to be similar, desirable, or experts (Rashotte 2007).

Many studies use the social network analysis technique to investigate complex sets of relationships between members ranging from interpersonal, to interorganizational, to international. Barnes (1954) was one of the first to use the term systematically when he discovered that although a community shared cultural values, most individuals made decisions with reference to personal contacts. Social network analysis has since been developed (Burt and Minor 1983; Friedkin 1980; Krackhardt 1987, 1990; Wasserman and Faust 1994) to include technological networks and derived effects; e.g. the long tail (Anderson 2006, Oestreicher-Singer and Sundararajan 2008) and user-generated content in online social networks (Oh et al. 2006). Another stream of research investigates central constructs in analysis of social network structure and interdependency between actors. These constructs describe partly overlapping forms of social network influence and they represent increasing levels of sophistication from quantitative-oriented measures toward comprehensive frameworks for understanding.

Thresholds are the proportion of adopters in a social system needed for an individual to adopt an innovation (Granovetter 1978). The threshold model (Valente 1996) follows Rogers' division of adopters and demonstrates that very low threshold individuals have thresholds two standard deviations lower than the average threshold for the network or community, and very high threshold individuals have thresholds two standard deviations higher than the average. Adoption thresholds can, therefore, be viewed as a characteristic of adopters.

Opinion leaders (Burt 1999; Oh et al. 2006; Valente and Davis 1999; Watts and Dodds 2007) are another construct when discussing social network influence. The definition of opinion leaders is more precisely "opinion brokers who carry information across the social boundaries between groups" (Burt 1999, p. 37). They are located at the edge of networks and act as brokers between groups and may induce two mechanisms: contagion by cohesion as opinion leaders diffuse information across groups, and contagion by equivalence as opinion leaders stimulate adoption within a group. 
Social contagion refers to an actor's decision to adopt an innovation depending on other actors' attitudes, knowledge, or behaviors concerning an innovation. Van den Bulte and Lilien (2001) identify a number of theoretical accounts of social contagion, from the literature, that describe different causal mechanisms of social contagion. These are information transfer (Katz and Lazarzfeld 1955), which may occur from both traditional and electronic media, normative pressures (Coleman et al. 1966), which occurs when an adopter feels discomfort, when peers, whose approval they value, have adopted an innovation but they have not. Also competitive concerns (Burt 1995), which can be viewed as opposed to normative pressures, and performance network effects (Katz and Shapiro 1986), which refers to the benefits of use that increase with the number of prior adopters of the innovation, are part of the social contagion construct.

Social learning is a related factor that affects an individual's choices when faced with substantial uncertainty in sampling of new innovations. It occurs through the observation of the individual's neighbors' choices (Tarde et al. 2008). A common explanation for such changes in behavior is that innovations create uncertainty about expected consequences, and to overcome uncertainty, individuals tend to interact with their social network to consult on others' adoption decisions through informational and normative social influences (Burkhardt and Brass 1990; Katz 1980; Katz and Tushman 1979). While learning occurs as a conscious process of interactions between related individuals, contagion may be the mere result of brief encounters with individuals who share information about the iPhone. Oh et al. (2006) built on Ellison and Fudenberg's (1993) prior research and found evidence for a number of mechanisms by which social influence is transmitted, such as preference for conformity and social learning.

Exploring how five closely related individuals made the decision to adopt the iPhone before it was made available through traditional supply chains, our focus is on understanding how early adopters of mobile devices overcome uncertainties related to shifts in technology. Hence, drawing on the adoption threshold, opinion leaders, social contagion, and social learning constructs our research question is

How and why does the social network of early adopters of the iPhone impact their decision to adopt?

\section{Research Method}

We chose the case study method to investigate the research question for a number of reasons: the case study method is preferred when how or why questions are being posed, when the extent of control of the investigator is little, when the focus is on a contemporary phenomenon and not historical events (Yin 2008), and when the focus is on understanding the dynamics within a single setting (Eisenhardt 1989). We conducted an exploratory study, as opposed to a descriptive or experimental study (Yin 2008), with the goal of investigating and reflecting upon how and why five closely related individuals made the decision to adopt an iPhone before it was made available through traditional supply chains.

Inspired by Eisenhardt's (1989) process of building theory from case study research, we adopted a similar conceptual framing throughout our investigation, 
although our goal was not theory building in particular, but rather exploration and presentation of empirical insights. We first identified the research question and adopted four social network concepts as a priori framing constructs. We then selected specific early adopters of the iPhone as our case material to help answer the research question. After generating an interview guide, based on the identified theoretical constructs, and while collecting data, we initiated the analysis phase. In this phase, we analyzed and reflected upon the data to present new insights. As Eisenhardt emphasizes, this was a highly iterative process.

\subsection{The Research Context}

The case focuses on five individual mobile users who adopted the iPhone prior to its official release in Denmark. Denmark is among the leading countries in the use of mobile devices and communication services (Economist Intelligence Unit 2008) and is, therefore, an appropriate venue for studying adoption of the iPhone at this specific time. The way in which early adopters surmount the uncertainties related to adoption of new mobile devices is particular interesting since they experience high switching costs because of lack of references to imitate or expert users to consult. Purposive sampling provided direct access to rich data about these individuals, their mutual relationships, and their interactions with other people and information sources. Purposive sampling techniques are primarily used in qualitative studies, when the aim is to select individuals based on a specific purpose associated with answering the research question (Teddlie and Yu 2007) and extending emergent theory (Eisenhardt 1989). The aim was to gain access to a group of closely related individuals to determine how their mutual relationship as well as their wider social network influenced their decision to adopt the iPhone at this time and why.

People with similar characteristics, tastes, and beliefs may associate in the same social networks (Manski 2000) and our sampling criteria were, therefore, that the group of individuals should be homogenous with similar characteristics and interests, and they should be part of the same social network. Homogenous sampling was chosen, as the aim is to understand and describe the decision to adopt an iPhone in a particular group of early adopters. The participants were, therefore, similar with respect to several variables, such as demographics and experience with mobile phones. To recruit the five individuals, one author had access to one individual who then contacted other individuals in his network who had adopted the iPhone. Our investigation is hence based on multilevel analysis. We observed and analyzed the behavior of the five individuals as a group while at the same time focusing on each individual, his social network, and decision making.

\subsection{Data Collection and Analysis}

The study employed qualitative methods to understand the affluent nature of mobile users' thought processes when overcoming uncertainties and adopting a new mobile device. The data collection took place from April 2008 to July 2008. It involved techniques such as semi-structured interviews, archival records, and data collected from a specific discussion forum on the Internet. The triangulation of data collection methods provides stronger support in the exploration of the research question 
(Eisenhardt 1989). The semi-structured interviews lasted from 60 to 80 minutes. The interview guide consisted of five main parts: demographics, the user's mobile device history, the user's iPhone history, the closed social network consisting of the five individuals, as well as each individual's extended network, and finally the adoption decision. Table 1 shows a description of the five main themes upon which the interview guide was based.

Table 1. The Interview Guide

\begin{tabular}{|l|l|}
\hline \multicolumn{1}{|c|}{ Theme } & \multicolumn{1}{c|}{ Description } \\
\hline Demographics & Demographic data \\
\hline Mobile device history & Experience with mobile devices \\
& Purpose of the device \\
& Experience with related products \\
\hline iPhone history & Experience with the iPhone prior to adoption \\
& and after adoption \\
& Thoughts on future technological acquisitions \\
\hline Social network & The network of the five individuals \\
& The extended network of each individual \\
\hline Adoption decision & Information gathering. \\
& Thoughts prior to adoption of device \\
& The actual decision \\
& After receiving the device \\
\hline
\end{tabular}

The analysis phase was broken down into three phases (Eisenhardt 1989). The first phase focused entirely on both the individual level and involved a detailed description of each of the five early adopters based on the main themes from the interview guide (Table 1). The second phase focused on the individual level as well as the group as a whole and it consisted of analyses that built on the descriptions from the first phase to explore how the four constructs - social contagion, social learning, opinion leaders, and adoption threshold-could explain the decision to adopt the iPhone before it was commercially available in Denmark. The third phase focused on explicating contributions to the literature by systematically identifying and reflecting on the empirical insights in relation to the existing literature.

\section{Results}

\subsection{Characterizing the Group of Adopters}

Several methods for categorizing adopters exist; the most well known are those by Rogers (2003) and Ryan and Gross (1943, 1950). These methods are, however, not predictive and do not provide insights into how the iPhone is received before it has gone through its adoption curve. Constantiou et al.'s (2007) categorization of mobile adopters is developed for the purpose of dividing mobile users into distinct groups 
based on their usage behavior. Users can be categorized as talkers, writers, photographers, and surfers. Each level is consecutive and, therefore, writers are also talkers, photographers are also talkers and writers, and surfers are also talkers, writers, and photographers.

Table 2 provides a description of the observed five mobile users. ${ }^{3}$ They are all male, in their early to mid thirties, and they have extensive experience with mobile phones, which is apparent in years of experience with mobile devices, number of mobile devices, and service experience. The demographic data shows a homogenous group of individuals consisting of adopters of the surfer category. According to Constantiou et al.'s 2007 study, the typical surfer is male, between 20 and 40 years of age, has a higher education, and works in the private sector. Surfers seek information about new mobile phones regularly and are usually among the first to try out new mobile technologies and services. They like to experiment and find it fairly easy to make their mobile device perform as they wish.

Table 2. Description of Mobile Users Participating in the Study

\begin{tabular}{|c|c|c|c|c|c|}
\hline & Adam & Ben & Chris & David & Eric \\
\hline Gender & Male & Male & Male & Male & Male \\
\hline Age & 36 & 33 & 33 & 34 & 33 \\
\hline Occupation & $\begin{array}{l}\text { Private } \\
\text { sector }\end{array}$ & $\begin{array}{l}\text { Private } \\
\text { sector }\end{array}$ & $\begin{array}{l}\text { Private } \\
\text { sector }\end{array}$ & $\begin{array}{l}\text { Public } \\
\text { sector }\end{array}$ & $\begin{array}{l}\text { Private } \\
\text { sector }\end{array}$ \\
\hline $\begin{array}{l}\text { First mobile } \\
\text { device - year }\end{array}$ & 1995 & 2000 & 1994 & 2000 & 1994 \\
\hline $\begin{array}{l}\text { Number of mobile } \\
\text { devices }\end{array}$ & $\sim 7$ & $\sim 5$ & $\sim 14$ & $\sim 8$ & $\sim 20$ \\
\hline Bought iPhone & Dec 2007 & Mar 2008 & Mar 2008 & Jan 2008 & Sep 2007 \\
\hline $\begin{array}{l}\text { Previous mobile } \\
\text { device }\end{array}$ & \begin{tabular}{|l} 
Sony \\
Ericsson \\
W950i \\
\end{tabular} & \begin{tabular}{|l} 
Sony \\
Ericsson \\
K800i \\
\end{tabular} & Nokia N73 & \begin{tabular}{|l} 
Sony \\
Ericsson \\
K810i \\
\end{tabular} & Nokia N95 \\
\hline Use of services & $\begin{array}{l}\text { Talk, SMS, } \\
\text { e-mail, } \\
\text { calendar, } \\
\text { Internet, } \\
\text { MMS, } \\
\text { Camera, } \\
\text { Mp3, } \\
\text { Games, } 3^{\text {rd }} \\
\text { party } \\
\text { software } \\
\text { (e.g., } \\
\text { maps) } \\
\end{array}$ & $\begin{array}{l}\text { Talk, SMS, } \\
\text { e-mail, } \\
\text { calendar, } \\
\text { Internet, } \\
\text { MMS, } \\
\text { Camera, } \\
\text { Mp3, } \\
\text { Games, } 3^{\text {rd }} \\
\text { party } \\
\text { software } \\
\text { (e.g., } \\
\text { maps) } \\
\end{array}$ & $\begin{array}{l}\text { Talk, SMS, } \\
\text { e-mail, } \\
\text { calendar, } \\
\text { Internet, } \\
\text { Mp3, } 3^{\text {rd }} \\
\text { party } \\
\text { software } \\
\text { (e.g., } \\
\text { maps) }\end{array}$ & $\begin{array}{l}\text { Talk, SMS, } \\
\text { e-mail, } \\
\text { calendar, } \\
\text { Internet, } \\
\text { MMS, } \\
\text { Camera, } \\
\text { Mp3, } 3^{\text {rd }} \\
\text { party } \\
\text { software } \\
\text { (e.g., } \\
\text { maps) }\end{array}$ & $\begin{array}{l}\text { Talk, SMS, } \\
\text { e-mail, } \\
\text { calendar, } \\
\text { Internet, } \\
\text { MMS, } \\
\text { Camera, } \\
\text { Mp3, } \\
\text { Games, } 3^{\text {rd }} \\
\text { party } \\
\text { software } \\
\text { (e.g., maps) }\end{array}$ \\
\hline Service experience & Surfer & Surfer & Surfer & Surfer & Surfer \\
\hline
\end{tabular}

\footnotetext{
${ }^{3}$ The identity of the five adopters is disguised.
} 
Table 3. Facebook Friends, April 2008 and April 2009

\begin{tabular}{|l|c|c|}
\hline & April 2008 & April 2009 \\
\hline Adam & 890 & 1531 \\
\hline Ben & 124 & 143 \\
\hline Chris & 635 & 1089 \\
\hline David & 194 & 373 \\
\hline Eric & 672 & 2000 \\
\hline
\end{tabular}

The five adopters have more characteristics in common. They display a positive attitude toward change and science, which is apparent in their interest in obtaining the iPhone even before its release in the United States. They already used most functions on their previous mobile devices-all smartphones. The users seem good in coping with risk and uncertainty, as they bought the iPhone from the United States and were forced to unlock and jailbreak the phone before being able to use it. They are highly interconnected in their social networks measured in number of Facebook "friends" (Table 3), which increases the flow of information. They furthermore benefit from vast exposure to media that delivers information about topics of interest (both mass media and interpersonal media channels, such as a discussion forum in which they participated). They are active information seekers and they display a considerable amount of knowledge of technological innovations.

The five adopters are furthermore highly interconnected as suggested by Table 4 , showing the number of Facebook friends the five adopters have in common. This pattern of Facebook friends relates to Dunbar (1995), who initially used cross-cultural studies to predict that humans socialize in groups of approximately 150 individualsalso referred to as the Dunbar number. Later Hill and Dunbar (2002) raised the question of whether social networks in modern, postindustrial societies exhibit a comparable pattern, and they found that social networks are still constrained to 150 due to possible limits in the capacity of the human communication channel.

\subsection{Evidence for Individual Adoption Decisions}

The five adopters decided to adopt the iPhone at different points in time ranging from September 2007 to March 2008. In the following, we present each individual adopter and his reflections leading to the actual adoption decision.

Table 4. Number of Friends in Common, Facebook, April 2008

\begin{tabular}{|l|c|c|c|c|c|}
\hline & Adam & Ben & Chris & David & Eric \\
\hline Adam & $\mathbf{8 9 0}$ & 115 & 254 & 115 & 165 \\
\hline Ben & 115 & $\mathbf{1 2 4}$ & 96 & 27 & 105 \\
\hline Chris & 254 & 96 & $\mathbf{6 3 5}$ & 96 & 155 \\
\hline David & 115 & 27 & 96 & $\mathbf{1 9 4}$ & 194 \\
\hline Eric & 165 & 105 & 155 & 105 & $\mathbf{6 7 2}$ \\
\hline
\end{tabular}


Adam, 36 years of age, holds a leading position in a private company within the music industry. He obtained his first mobile device in 1994 and acquires a new device approximately every second year. He acquired the iPhone in December 2007, five months after its release in the United States. He waited five months to buy the iPhone even though he always knew he had to attain it, as he was concerned with the lack of 3G. Adam had possessed iPods for years; however, he is not particularly into Apple's products. He monitored the exposure of the iPhone in the media and noticed an explosion in the development of techniques on how to jailbreak the firmware on the iPhone. He is, furthermore, a member of the discussion group, HF, on the Internet where he and others discussed the recent development in releasing the iPhone and how to unlock and jailbreak the device. He decided to buy the device when a friend let him try out the iPhone.

Ben is 33 years old. He holds an analyst position in a private company and creates music in his leisure time. He obtained his first mobile device in 2000 and acquires a new device roughly every second year. He obtained his iPhone in March 2008 when he travelled to the United States, and he acquired several copies and brought them to Denmark to his friends. Ben has possessed Mac computers for approximately five years, mostly for music production purposes, and iPods for four years. He is an Apple enthusiast and was initially exposed to the iPhone through the media. $\mathrm{He}$ watched the MacWorld Expo presentation of the iPhone on the Internet. He also discussed the device with friends and acquaintances and was convinced early on that he would obtain the iPhone. Ben decided to adopt based on two considerations. First, the instructions on the Internet on how to unlock and jailbreak the phone had advanced and it was now rather easy to do. Second, he was traveling to the United States and could therefore easily get access. He says, "When I held it the first time, I just knew I had to get it now. I didn't want to wait any longer."

Chris is 33 years old and works as a consultant in a private company. He obtained his first mobile device in 1994 and acquires a new device approximately every year. He bought his iPhone March 2008. Chris went to the United States in December 2007 and seriously thought of acquiring the device at that time, but decided to wait. His mobile device at the time suddenly got slower and he decided to obtain the iPhone when traveling to the United States again in March 2008. Chris has been in possession of PowerBooks and iPods since 1999 and can be labeled an Appleonsumer. He followed the presentation and release of the iPhone through the media and participated in the discussion forum HF. He had made a decision to acquire the phone even before the release. When it was released in the United States, he did not have an excessive need and thought that the device would come to Denmark quickly in a $3 \mathrm{G}$ version. However, as the Danish release was extended and his mobile device at the time became slow, he decided he couldn't wait any longer. He added, "I will definitely buy the phone when it comes to Denmark in a $3 \mathrm{G}$ version."

David is 34 years old and holds a project management position in a public institution. He obtained his first mobile device in 2000, acquires a new device approximately every year, and he bought his iPhone in January 2008. David has been using his household's Mac hardware and software although he states that since 2001 the only Apple product he has owned himself is the iPod. David has been aware of the iPhone since before Apple's presentation and he always knew he would acquire one. When asked why, he stated, "It's partly a question of practicality; gathering all 
gadgets into one, so that you don't have to carry all these devices in your pockets. And it's partly a question of being able to use the services that the network operators have tried to push for so long. We now have a device that shows applications as if you were sitting in front of your computer. Now mobility is for real." He was concerned that the device wasn't made for the Danish market; however, he finally decided to obtain the iPhone not waiting for the Danish release: "The iPhone was too cool and I don't want to wait for some decelerated network operator to get their stuff together... it is an unheard situation, that it's not just there, and agreements have to be made."

Eric, 33 years of age, holds a project coordinator position in a private company and performs music in his leisure time. He obtained his first mobile device in 1994 and acquires a new device approximately two times a year. He acquired his iPhone in September 2007. Eric has extensive knowledge about Apple's computers, as he has been using both iMac and MacBook for several years. However, he never had an iPod before he acquired the iPhone. Eric has been aware of the iPhone since before it was presented at the MacWorld Expo conference: "That was the first time pictures were revealed. Here it is. But even before that, in 2006, there was a lot of speculation on what the phone would look like. I remember a lot of photos of white phones that matched the look of the white MacBooks." He noticed that whenever Apple releases a new product they create a plethora of hype and he believes they succeeded in building up excitement about the iPhone. It became prestigious to possess an iPhone.

\subsection{Analyzing Social Network Influences}

Adoption thresholds of collective behavior are the proportion of adopters in a social system needed for an individual to adopt an innovation (Granovetter 1978).

We asked the iPhone adopters how many people in their network that they knew had adopted the iPhone prior to them, Adam replied five and the rest replied one. Given that they had between 124 and 890 Facebook friends at the time, the proportion of iPhone adopters in their networks was relatively small; between 0.0015 percent (Chris and Eric) and 0.08 percent (Ben). At the time of the interviews ${ }^{4}$ the five adopters believed that between 10 and 60 people in their extended network had adopted the iPhone. This indicates that all five adopters have a low network threshold in regard to their extended network. Eric was the first to adopt the iPhone (September 2007) and is also the person with the lowest network threshold in regard to his close network. Adam was also aware of a benefit of adopting early: "It is still a bit nerdy. You can't go down in the local store and buy one yet." Hence, the five early iPhone adopters all have a low network threshold both in regard to their close network and their extended network.

Opinion leaders are "opinion brokers who carry information across the social boundaries between groups" (Burt 1999, p. 37) to stimulate contagion by cohesion or contagion by structural equivalence.

4 The interviews were conducted in April 2008; eight months after the first adopters in the study acquired their iPhone, one month after the latest adopters in the study adopted the iPhone, and three months before the iPhone was released on the Danish market. 
When investigating the influence of opinion leaders in the network, we asked the five adopters how many contacts they had in common (Table 4) and how many contacts they had in their extended network (Table 3). The number of Facebook friends is the most precise measure of the adopters' networks we could obtain. Adam, who had the highest number of Facebook friends at the time of the interview, reflected that the high number is a consequence of him working in the music industry, and he does not have frequent contact with most contacts. Chris' and Eric's high number of Facebook friends are also the result of their time spent socializing with individuals through the music scene. The five adopters have between 27 (Ben and David) and 254 (Adam and Chris) friends in common. According to all of them, there was no single person who brought information about the iPhone into their extended networks. Although they all had decided to obtain the iPhone at some point, it was the testing of the device from one friend that stimulated the actual acquisition. All adopters claim they actively sought information about the iPhone as soon as they became aware of it. There is hence no evidence that opinion leaders played a significant role in the adoption decision made by the five adopters.

Social contagion refers to an individual's decision to adopt an innovation depending on other individuals' attitudes, knowledge, or behaviors concerning the innovation (Van den Bulte and Lilien 2001). Mobile adopters with higher numbers of direct ties have greater opportunities to disseminate and receive information about the iPhone because they have more choices (Burt 1999; Granovetter 1973). Thus the number of direct ties captures the power and the opportunities to receive information about the iPhone. According to statistics on Facebook, the average user on Facebook has 120 friends, ${ }^{5}$ which is also supported by a small-scale investigation conducted by The Economist (Kluth 2009). All five iPhone adopters in this study have a number of Facebook friends higher than the average, which increases the likelihood of getting contaminated with attitudes, knowledge, and behaviors toward the iPhone from their Facebook network.

As identified by Van den Bulte and Lilien (2001), four mechanisms may cause social contagion. Information transfer occurs both from traditional media, such as newspapers, television, and Internet-based media, such as podcasts, to the individual mobile users as well as between the individuals. The five adopters all received information and news about the iPhone from various types of media and all except Ben were part of a particular discussion forum on the Internet that, aside from the main topic of the forum (electronic music), discussed various topics including the latest news on the release of the iPhone. As the five adopters are part of the same social setting and met regularly, they also exchanged information directly. Adam even claims that he decided to buy the iPhone at the exact moment a friend in his extended network let him try out his iPhone. He says, "It is my clear belief that this is where something snaps. One thing is what you read...everybody's skeptic but that is only until you get a demonstration." Hence, information transfer and demonstrations from both different media and the social network had significant influence on each individual's decision to adopt the iPhone.

5 Facebook Press Room (http://www.facebook.com/press/info.php?statistics; accessed August 16, 2009). 
Normative pressure occurs when the mobile user experiences discomfort, when peers, whose approval they value, have adopted an innovation but they have not. When asked, how many people in their social network they believed owned an iPhone before they bought theirs, Adam answered five, and the four other adopters answered one. There is, therefore, no evidence that normative pressures influenced the iPhone adopters.

Competitive concerns can be viewed as being opposed to normative pressures and it appears that it influenced the individual's decision to adopt the iPhone. As Eric stated, "The iPhone has a high prestige factor that will probably descend when it is released in Denmark." He further argued that the iPhone attracts a lot of attention from peers who do not own an iPhone. Adam and Ben have a similar view. David, on the other hand, does not feel that competition had any influence on his adoption decision. He believes that the iPhone is simply the best phone on the market, a position with which Chris agrees.

Performance network effects refer to the benefits of use that increase with the number of prior adopters of the innovation. These effects are apparent for mobile devices in general, as the benefits of communication via such a device increases with the number of prior users. As all iPhone adopters studied had advanced mobile devices prior to the iPhone, they did not exhibit network effects from adopting the iPhone.

Social learning is related to social contagion. As mobile users are faced with uncertainty in the decision to adopt the iPhone, they may observe their neighbor's choices and interact with their social network to consult on their adoption decision through informational and normative social influences (Burkhardt and Brass 1990; Katz 19890; Katz and Tushman 1979).

When collecting data on social learning, we asked the adopters if they would be able to make the iPhone work when they received it and if they depended on other people in their network to help them. All five adopters replied they had at least one friend they relied on to help in case they weren't able to make it work by themselves; however, they all initially depended on themselves to be able to unlock and jailbreak the phone based on instructions from a website. David made the purchasing decision when he found that "the instructions became easy to comprehend and I could see myself fix everything; installation of new applications, jailbreaking, unlocking, update firmware-everything that had to do with the iPhone, I could do it myself without being dependent on others." Adam found that "it became a competition for Mac nerds to determine who could break the latest firmware. So, the information and software on the web is quite good." There is, therefore, evidence that social learning played an important part in the individual's decision to adopt the iPhone.

\section{Discussion}

We have presented a case study investigating the behaviors and decisions of early adopters of the iPhone. We analyzed both individual adoption decisions as well as social network influences. In contrast to existing studies on early adoption (Kauffman and Techatassanasoontorn 2009; Wozniak 1987), our study was based on a qualitative approach in which we used four complementary social network influence constructs: 
adoption threshold, opinion leaders, social contagion, and social learning. Interestingly, these analyses confirmed some previously identified insights, but also questioned earlier findings.

The study confirms that contemporary mobile devices still revolutionize many aspects of everyday life (Green et al. 2001) as they combine many gadgets into one stylish device. The study also shows that when facing uncertainty, adoption decisions emerged as a combined result of individual adoption reflections and major influences from the social network and the behaviors observed within the network. In fact, the analyses confirmed that network structures impact the decision to accept a mobile device (Katz 1961; Rogers 2003; Vidgen et al. 2007) while also revealing new details on social network influences on early adoption decisions.

Drawing from existing utilitarian research on mobile adoption studies (Carlsson et al. 2000; Pedersen and Ling 2002) as well as studies that have established correlation between an individual's social network and the decision to adopt (Dickinger et al. 2008; Lu et al. 2005), our study provides a detailed description of adopters that faces high uncertainties when adopting the iPhone before it was readily available. We thereby offer new insights into how early adopters of mobile devices overcome uncertainties related to shifts in technology. Explaining these behaviors can be challenging, and relying on too simplistic models might not suffice. Therefore, we relied on multiple perspectives and multiple levels of analyses and were open to question insights from traditional adoption theory. Such an explorative, multiconstruct and multilevel perspective has previously been left unexamined.

Our study supports several insights from previous work on mobile adoption. Lu et al. (2005) found that perceived ease of use of wireless Internet services on mobile devices had a direct effect on the intention to adopt the service. Our study supports this finding as the early adopters of the iPhone relied on easy to use instructions on how to unlock and jailbreak their iPhone as well as their network to provide the help they needed. Similarly, Dickinger et al. (2008) found that attitude towards "push-totalk" services had a positive effect on the intention to use the service. Our study shows that early adopters of the iPhone had a positive attitude toward the device long before it was released, contributing to their intention to adopt.

Our study also supports previous research on categorization of adopters. Lu et al. found that personal innovativeness had an impact on intention to adopt wireless Internet services via mobile technology. Constantiou et al. (2007) divided mobile users into categories that describe several traits of each category. The personal innovativeness construct, and Constantiou et al.'s description of the surfer user, fits well with our early adopters, who all belong to the surfer category. Wozniak (1987) studied early adoption of new technology in organizations and found that adoption behavior is a "human capital intensive activity" that depends on acquired human capital and investment into receiving adoption information. Our study confirms that the social influence construct information transfer, which is part of social contagion, had significant impact on early adoption decisions.

More explorative studies of social influences are needed to develop and validate these findings and other influences than the ones we considered may also have had an impact. The artifact itself possesses some unique characteristics that were emphasized by the adopters: design characteristics as well as utilitarian characteristics. As Orlikowski and Iacono (2001) argue, the IT artifact itself tends to be taken for granted 
in research. We acknowledge the importance of the artifact, and recognize that it had significant impact on our adopters' decision making beyond the focus of our analyses. It is also of interest to look at Apple's marketing effort. Van den Bulte and Lilien (2001) found that when they control for marketing efforts in the diffusion of the drug Tetracycline, contagion effects disappear. It could, therefore, be that the heavy promotion of the iPhone by Apple, the hype that was created by the media and the public, and the limited supply of iPhones (Lynn 1991; Verhallen 1982, Verhallen and Robben 1994) were important influences on the five adopters. This observation is furthermore related to Leibenstein's (1950) "snob effect." Although the five adopters did not see themselves as snobs, they agreed that owning the iPhone at the time was prestigious.

\section{References}

Anderson, C.: The Long Tail: Why the Future of Business is Selling Less of More. Harvard Business School Press, Boston (2006)

Agarwal, R., Prasad, J.: Are Individual Differences Germane to the Acceptance of Information Technologies? Decision Sciences 30(2), 361-391 (1999)

Barnes, J.A.: Class and Committees in a Norwegian Island Parish. Human Relations (7), 39-58 (1954)

Bauer, H.H., Reichardt, T., Barnes, S.J., Neumann, M.M.: Driving Consumer Acceptance of Mobile Marketing: A Theoretical Framework and Empirical Study. Journal of Electronic Commerce Research 6(3), 181-192 (2005)

Bergman, E.: Information Appliances and Beyond. Morgan Kauffman, San Francisco (2000)

Brightman, J.: PC Game Sales Bring U.S. Industry to $\$ 18.85$ Billion in 2007, GameDaily (2008), http: / /www.gamedaily.com/articles/news /

pc-game-sales-bring-us-industry-to-1885-billion-in-07 (accessed July 17, 2008)

Burkhardt, M.E., Brass, D.J.: Changing Patterns or Patterns of Change: The Effects of a Change in Technology on Social Network Structure and Power. Administrative Science Quarterly (35), 104-127 (1990)

Burt, R.S.: Structural Holes: The Social Structure of Competition. Harvard University Press, Cambridge (1995)

Burt, R.S.: The Social Capital of Opinion Leaders. Annals (566), 37-54 (1999)

Burt, R.S., Minor, M.J.: Applied Network Analysis. Sage, Newbury Park (1983)

Campbell, S.W., Russo, T.C.: The Social Construction of Mobile Telephony: An Application of the Social Influence Model to Perceptions and Uses of Mobile Phones Within Personal Communication Networks. Communication Monographs 70(4), 317-334 (2003)

Carlsson, C., Carlsson, J., Hyvönen, K., Puhakainen, J., Walden, P.: Adoption of Mobile Devices/Services: Searching for Answers with the UTAUT. In: Proceedings of the 39th Hawaii International Conference on System Sciences, pp. 132-142. IEEE Computer Society Press, Los Alamitos (2000)

Chuang, M.C., Chang, C.C., Hsu, S.H.: Perceptual Factors Underlying User Preferences Toward Product Form of Mobile Phones. International Journal of Industrial Ergonomics 27(4), 247-258 (2001)

Coleman, J.S., Katz, E., Menzel, H.: Medical Innovation: A Diffusion Study. Bobbs-Merrill, Indianapolis (1966) 
Constantiou, I.D., Damsgaard, J., Knutsen, L.: The Four Incremental Steps Toward Advanced Mobile Service Adoption. Communications of the ACM 50(6), 51-55 (2007)

Dickinger, A., Arami, M., Meyer, D.: The Role of Perceived Enjoyment and Social Norm in the Adoption of Technology with Network Externalities. European Journal of Information Systems (17), 4-11 (2008)

Dunbar, R.I.M.: Neocortex Size and Group Size in Primates: A Test of the Hypothesis. Journal of Human Evolution 28(3), 287-296 (1995)

Economist Intelligence Unit. E-Readiness Rankings 2008: Maintaining Momentum, The Economist (2008),

http://a330.g.akamai.net//330/5828/0080331202303/

graphics.eiu.com/upload/ibm_ereadiness_2008.pdf

Eisenhardt, K.M.: Building Theories from Case Study Research. Academy of Management Review 14(4), 532-550 (1989)

Ellison, G., Fudenberg, D.: Rules of Thumb for Social Learning. Journal of Political Economy 101(4), 612-643 (1993)

Fischer, C.S.: America Calling: A Social History of the Telephone to 1940. University of California Press, Berkeley (1994)

French, J., Raven, B.: The Bases of Social Power. In: Cartwright, D. (ed.) Studies in Social Power, pp. 159-167. Institute for Social Research, Ann Arbor (1959)

Friedkin, N.: A Test of Structural Features of Granovetter's Strength of Weak Ties. Social Networks (2), 411-422 (1980)

Granovetter, M.: The Strength of Weak Ties. America Journal of Sociology 78(6), 1360-1381 (1973)

Granovetter, M.: Threshold Models of Collective Behavior. American Journal of Sociology 83(6), 1420-1443 (1978)

Green, N., Harper, R.H.R., Murtagh, G., Cooper, G.: Configuring the Mobile User: Sociological and Industry Views. Personal and Ubiquitous Computing (5), 146-156 (2001)

Haddon, L. (ed.): Communications on the Move: The Experience of Mobile Telephony in the 1990s, COST 268 Report, Talia, Farsta, Sweden (1997)

Hall, B.H., Khan, B.: Adoption of New Technology. NBER Working Paper No. W9730, National Bureau of Economic Research (2003)

Hill, R., Dunbar, R.: Social Network Size in Humans. Human Nature 14(1), 53-72 (2002)

Hong, S.-J., Tam, K.Y.: Understanding the Adoption of Multipurpose Information Appliances. Information Systems Research 17(2), 162-179 (2006)

Katz, R.: The Social Itinerary of Technical Change: Two Studies on the Diffusion of Innovation. Human Organization 20(2), 70-82 (1961)

Katz, R.: A Theory of Parties and Electorial Systems. The Johns Hopkins University Press, Baltimore (1980)

Katz, R., Lazarsfeld, P.F.: Personal Influence. The Free Press, Glencoe (1955)

Katz, R., Shapiro, C.: Technology Adoption in the Presence of Network Externalities. Journal of Political Economy 94(4), 822-843 (1986)

Katz, R., Tushman, M.L.: Communication Patterns, Project Performance, and Task Characteristics: an Empirical Evaluation and Integration in an R\&D Setting. Organizational Behavior and Human Performance 23(2), 139-162 (1979)

Kaufmann, R.J., Techatassanasoontorn, A.A.: Understanding Early Diffusion of Digital Wireless Phones. Telecommunications Policy (33), 432-450 (2009)

Khalifa, M., Cheng, S.K.N.: Adoption of Mobile Commerce: Role of Exposure. In: Proceedings of the 35th Hawaii International Conference on System Sciences, pp. 1-7. IEEE Computer Society Press, Los Alamitos (2002) 
Kluth, A.: The Size of Social Networks. The Economist (2009),

http: / /www. economist.com/sciencetechnology/

displaystory.cfm?story_id=13176775 (accessed August 23, 2009)

Krackhardt, D.: Cognitive Social Structures. Social Networks (9), 109-134 (1987)

Krackhardt, D.: Assessing the Political Landscape Culture, Cognition and Power in Organizations. Administrative Science Quarterly (35), 342-369 (1990)

Laukkanen, T., Lauronen, J.: Consumer Value Creation in Mobile Banking Services. International Journal of Mobile Communications 3(4), 325-338 (2005)

Lee, Y.E., Benbasat, I.: Interface Design for Mobile Commerce. Communications of the ACM 46(12), 48-52 (2003)

Leibenstein, H.: Bandwagon, Snob, and Veblen Effects in the Theory of Consumers' Demand. Quarterly Journal of Economics (64), 183-207 (1950)

Lewis, W., Agarwal, R., Sambamurthy, V.: Spheres of Influence on Beliefs about Information Technology Use: An Empirical Study of Knowledge Workers. MIS Quarterly 27(4), 657$678(2003)$

Lu, J., Yao, J.E., Chun-Sheng, Y.: Personal Innovativeness, Social Influences and Adoption of Wireless Internet Services via Mobile Technology. Journal of Strategic Information Systems (14), 245-268 (2005)

Lynn, M.: Scarcity Effects on Value: A Quantitative Review of the Commodity Theory Literature. Psychology and Marketing 8(1), 45-57 (1991)

Lyytinen, K., Yoo, Y.: Research Commentary: The Next Wave of Nomadic Computing. Information Systems Research 13(4), 377-388 (2002)

Magni, M., Angst, C., Argarwal, R.: A Multilevel Investigation of Normative and Informational Influences on Extensiveness of Individual Technology Use. In: Proceedings of the 28th International Conference on Information Systems, Montreal, Quebec, Canada, December 9-12 (2007)

Manski, C.F.: Economic Analysis of Social Interactions. Journal of Economic Perspectives (14), 115-136 (2000)

Meehan, A.: The Impact of Mobile Data Terminal (MDT) Information Technology on Communication and Recordkeeping in Patrol Work. Qualitative Sociology (21), 225-254 (1998)

Moore, G.C., Benbasat, I.: Development of an Instrument to Develop Perceptions of Adopting an Information Technology Innovation. Information Systems Research 2(3), 192-222 (2001)

Nippert-Eng, C.: Home and Work: Negotiating Boundaries Through Everyday Life. University of Chicago Press, Chicago (1996)

Oestreicher-Singer, G., Sundararajan, A.: Recommendation Networks and the Long Tail of Electronic Commerce. Mimeo, Stern School of Business, New York University (2006)

Oh, H., Labianca, G., Chung, M.: A Multilevel Model of Group Social Capital. Academy of Management Review 31(3), 569-582 (2006)

Orlikowski, W.J., Iacono, C.S.: Research Commentary: Desperately Seeking the 'IT' in IT Research - A Call to Theorizing the IT Artifact. Information Systems Research 12(2), 121-134 (2001)

Palen, L., Salzman, M., Young, E.: Discovery and Integration of Mobile Communications in Everyday Life. Personal and Ubiquitous Computing 5(2), 109-122 (2001)

Patton, M.: Qualitative Research and Evaluation Methods. Sage Publications, Thousand Oaks (2001) 
Pedersen, P.E.: Adoption of Mobile Internet Services: An Exploratory Study of Mobile Commerce Early Adopters. Journal of Organizational Computing and Electronic Commerce 15(2), 203-222 (2005)

Pedersen, P.E., Ling, R.: Modifying Adoption Research for Mobile Internet Service Adoption: Cross-Disciplinary Interactions. In: Proceedings of the 37th Hawaii International Conference on System Sciences. IEEE Computer Society Press, Los Alamitos (2003)

Rashotte, L.: Social Influence. In: Manstead, A.S.R., Hewston, M. (eds.) The Blackwell Encyclopedia of Social Psychology, pp. 562-563. Blackwell Publishing, Malden (2007)

Rogers, M.E.: Diffusion of Innovations. The Free Press, New York (2003)

Ryan, B., Gross, N.C.: The Diffusion of Hybrid Seed Corn in Two Iowa Communities. Rural Sociology 8(1), 15-24 (1943)

Ryan, B., Gross, N.C.: Acceptance and Diffusion of Hybrid Corn in Two Iowa Communities. Iowa Agricultural Experiment Station. Research Bulletin No 372 (1950)

Sarker, S., Wells, J.D.: Understanding Mobile Handheld Device Use and Adoption. Communications of the ACM 46(12), 35-40 (2003)

Tarasewitch, P.: Designing Mobile Commerce Applications. Communications of the ACM 46(12), 57-60 (2003)

Tarde, G., Warren, H., Baldwin, J.M.: Social Laws: An Outline of Sociology (1899). Kessinger Publishing, Whitefish (2008)

Teddlie, C., Yu, F.: Mixed Methods Sampling: A Typology with Examples. Journal of Mixed Methods Research 1(1), 77-100 (2007)

Tscherning, H., Damsgaard, J.: Understanding the Diffusion and Adoption of Telecommunication Innovations: What We Know and What We Don't Know. In: León, G., Bernardos, A., Casar, J., Kautz, K., DeGross, J. (eds.) Open IT-Based Innovation: Moving Towards Cooperative IT Transfer and Knowledge Diffusion, pp. 41-62. Springer, Boston (2008)

Valente, T.W.: Social Network Thresholds in the Diffusion of Innovations. Social Networks 18(1), 69-89 (1996)

Valente, T.W., Davis, R.L.: Accelerating the Diffusion of Innovations Using Opinion Leaders. Annals of the American Academy of Political and Social Science (566), 55-67 (1999)

Van den Bulte, C., Lilien, G.: Medical Innovation Revisited: Social Contagion Versus Marketing Effort. American Journal of Sociology 106(5), 1409-1435 (2001)

Vidgen, R., Madsen, S., Kautz, K.: Mapping the Information Systems Development Process. In: Proceedings of IFIP WG8.6 Working Conference on IT Innovation, IFIP, Dublin, Ireland (2004)

Verhallen, T.M.: Scarcity and Consumer Choice Behavior. Journal of Economic Psychology 2(2), 299-321 (1982)

Verhallen, T.M., Robben, H.S.: Scarcity and Preference: An Experiment on Unavailability and Product Evaluation. Journal of Economic Psychology (15), 315-331 (1994)

Wang, S., Cheung, W.: E-Business Adoption by Travel Agencies: Prime Candidates for Mobile e-Business. International Journal of Electronic Commerce 8(3), 43-63 (2004)

Wasserman, S., Faust, K.: Social Network Analysis: Methods and Applications. Cambridge University Press, New York (1994)

Watts, D.J., Dodds, P.S.: Influentials, Networks, and Public Opinion Formation. Journal of Consumer Research 34(4), 441-459 (2007)

Wozniak, G.D.: Human Capital, Information, and the Early Adoption of New Technology. Journal of Human Resources 22(1), 101-112 (1987)

Yin, R.K.: Case Study Research: Design and Methods, 4th edn. Sage Publications, Thousand Oaks (2008) 


\section{About the Authors}

Heidi Tscherning received her Master's in Business Administration and Economics in 2000 from Copenhagen Business School, Denmark. She is currently a doctoral student at the Center for Applied ICT at Copenhagen Business School. Prior to joining the doctoral program, she worked as a project manager and IT management consultant in companies such as IBM, Novo Nordisk, and Systematic Software Engineering. Her research interests include adoption of technologies, with a particular interest in mobile devices and services and social networks. She recently visited the Polytechnic Institute of New York University (January 2009 to February 2010). Heidi can be reached by e-mail at htj.caict@cbs.dk.

Lars Mathiassen received his Master's degree in computer science from Aarhus University, Denmark, in 1975, his Ph.D. in informatics from Oslo University, Norway, in 1981, and his Dr. Techn. degree in software engineering from Aalborg University in 1998. He is currently GRA Eminent Scholar and professor in the Department of Computer Information Systems and co-founder of the Center for Process Innovation at Georgia State University. His research interests are in the areas of information systems and software engineering with a particular emphasis on process innovation. He is a coauthor of Computers in Context (Blackwell 1993), Object Oriented Analysis \& Design (Marko Publishing, 2000), and Improving Software Organizations (Addison-Wesley, 2002). He has served as a senior editor for MIS Quarterly and his research has been published in journals including Information Systems Research, MIS Quarterly, IEEE Transactions on Engineering Management, Communications of the ACM, Journal of the AIS, Information Systems Journal, and IEEE Software. Lars can be reached at Lars.Mathiassen@ eci.gsu.edu. 